\section{PENELITIAN PENGARUH KEKERASAN KOMPON SOL KARET SEPATU KANVAS DENGAN DAYA REKAT LEM}

Oleh : A. Buchori, Luciawati Sunarjo

The objective of the research is to know the influence of the hardness compound rubber sole for canvas shoes by cemented resistant. Rubber sole compound is made from natural rubber (pale crepe) with the addition of ingredient such as : softener, activator, anti oxidant, filler, accelerator and vulcanizing agent. The result of rubber sole is : A, B, C, D, E, F compound with the hardness test : $52,53,54,55,56$ and 57 Shore A. After sole is roughed, than sole and canvas upper shoes is laminated by cement, after 3 minute than the joint is done by pressing it with varying pressure 10,20 and $30 \mathrm{~kg} / \mathrm{cm} 2$ along $15 \mathrm{sec}$. Then it should be tested their cemented resistant. The test is actually able to fulfill the specification of SNI 12-0171-1987 "Sepatu Kanvas Dengan Sol Karet Untuk Olah Raga". The best tested of the hardness 53 Shore A (compound B) the value : $21,2259 \mathrm{~N} / 6 \mathrm{~mm}$.

\section{INTISARI}

Penelitian ini bertujuan untuk mengetahui pengaruh kekerasan kompon sol karet sepatu kanvas dengan daya rekat lem. Kompon sol karet yang digunakan dibuat dari karet alam (Pale Crepe) dengan ditambah bahan pembantu (ingredient) seperti bahan pelunak, pengaktif, anti oksidan, pengisi, pencepat dan zat pemvulkanisasi. Hasil sol karet adalah kompon A, B, C, D, E, F dengan hasil uji kekerasan : 52,53 , $54,55,56$ dan 57 Shore A. Setelah sol dikasarkan kemudian sol dan atasan sepatu kanvas diulas dengan lem, setelah 3 menit kemudian dilakukan penggabungan dengan dipres menggunakan variasi tekanan : 10, 20 dan $30 \mathrm{~kg} / \mathrm{cm} 2$, selama 15 detik, kemudian diuji ketahanan rekatnya. Hasil uji memenuhi persyaratan SNI 120171-1987 "Sepatu Kanvas Dengan Sol Karet Untuk Olah Raga". Hasil uji terbaik dengan kekerasan : 53 Shore A (kompon B) dengan nilai : 21,2259 N/6 mm.
PENDAHILIAN

Kelemahan sepatu kanvas yang ada dipasah uran sat ini adalah ikation antara sol dengan atasannya mudah lepas, salah satu kemunghinan penyebabnyat adalah kekerasannya tidak sesuai dengan kam yang "digunakan. Untuk itu perlu dilakukan Penelitian pengatruh kekerasan sol karet, terhadap daya rekat lem. Untuk mendapathan kekerasan sol haret, dizunaka $a_{10}$ bahan pengisi $\mathrm{Ca} \mathrm{CO}_{3}$ Kapur tanah atau $\mathrm{Ca} \mathrm{CO}_{3}$ mi digunathan dalam bo bantuk buhuk atau powder. herwarna putih dengan ukuran partihel dihawah I/ $/ 00$ mesh. Ca $\mathrm{CO}_{3}$ mem-

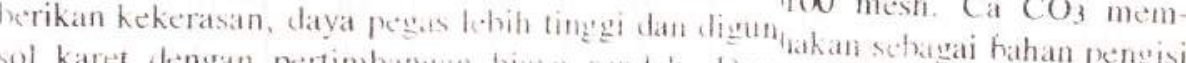
sol karet dengan pertimhangan hitya rendah. Dapeak diganahan pada poduk yang dimoulding dan memperhatiki kemampuan perit nukatan dari harang-barang aret yang diekstrusi (6)

Lem yang digunakan adalah $\mathrm{km}$ hasil penclit, bangan dan Penelitian kulit Tahun $1983 / 198.4$ K lian Proyeh Balai Pengem. dipengaruhi jumlah filler yang ditambahkin, seding chetasall sol haret sangit terhadap kanvas tidak hanya teryantung pulates an kehuatan rekat sol kitet benda yang dilem, tetapi juga tergantung palat tingh tian holici dari lem atau katan yang direkathan (4).

Untuk mendapatkin daya rekat yatag optimum

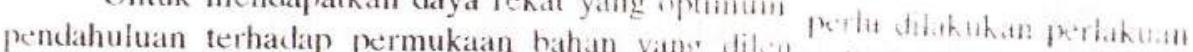

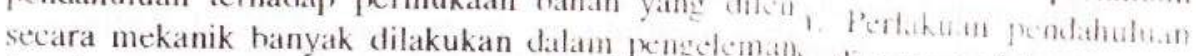

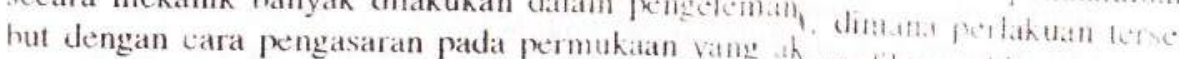

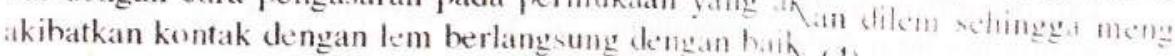

Tujuan Penelitian :

Untuk mengetahui sejauh mana pengaruh hek sepatu kanvas terhadap ketahanan rekat lem.

\section{MATERI DAN METODA} Pada percobaan ini mula-mula dihuat kompon sol karet sepatu kanvas
untuk olah raga dengan formulasi sehagai berikut:

Tabel 1: Formulasi kompon sol karet sepatu kahvas untuk olah raga.

Vol. XII No. 22 Th. 1996/1997 


\begin{tabular}{|c|c|c|c|c|c|c|}
\hline Bahan & $\Lambda$ & B & C: & 1) & li & F \\
\hline Pale crepe & 100 & 100 & 100 & 100 & 100 & 100 \\
\hline Asam stearat & 0,5 & 0,5 & 0.5 & 0,5 & 0,5 & 0.5 \\
\hline $\mathrm{ZnO}$ & 10 & 10 & 10 & 10 & 10 & 10 \\
\hline $\mathrm{MgCO}_{3}$ & 20 & 20 & 20 & 20 & 20 & 20 \\
\hline $\mathrm{CaCO}$ & 65 & 70 & 75 & 80 & 8.5 & 90 \\
\hline Naphthenic Oil & 2 & 2 & 2 & 2 & 2 & 2 \\
\hline Paraffin wax & 0.5 & 0,5 & 0,5 & 0,5 & 0.5 & 0,5 \\
\hline $\mathrm{TiO}_{2}$ & 10 & 10 & 10 & 10 & 10 & 10 \\
\hline PBN & 1 & 1 & 1 & 1 & 1 & 1 \\
\hline M B T S & 0,4 & 0.4 & 0,4 & 0,4 & 0.4 & 0,4 \\
\hline $\mathrm{MBC}$ & 0.4 & 0,4 & 0.4 & 0,4 & 0.4 & 0.4 \\
\hline $\mathrm{T} \mathrm{M}$ & 0,2 & 0,2 & 0,2 & 0,2 & 0,2 & 0,2 \\
\hline Sulphur & 2 & 2 & 2 & 2 & 2 & 2 \\
\hline
\end{tabular}

contoh uji minimum $6 \mathrm{~mm}$. Cuplikan diktakkan pada hidang datar alat uji. kemudian tekan cuplikan dengan alat durometer Shore A. Besarnya pene kanan pada cuplikan identik dengan kekerasan dan dapat dilihat pada skala Hasil uji adalah rata-rata dari 5 kali pengukuran

2. Ketahanan rekat

Pembuatan contoh uji :

Sol karet yang berupa slab direkatkan pada hain kansas. Mula mula dibuat contoh uji dengan ukuran
- Panjang
$100 \mathrm{~mm}$
- Lebar
$30 \mathrm{~mm}$
- Tebal
$3 \mathrm{~mm}$

Selanjutnya permukaan sol karet yang akan dilem dikasarkan denean hertas amplas nomor 2, waktu pengamplasan rata rata 30 ) detik tiap contoh uji. pengasaran dilakukan dengan mesin amplas, sehagai atasan digunakan kain kanvas. Daerah pengeleman adalah sepanjang : $50 \mathrm{~mm}$ dan seluruh lehatrmy yaitu : $30 \mathrm{~mm}$. Pengeleman dilakukan pengolesan 2 sisi, masing-masing । kali olesan, waktu pengeringan 3 menit. Kemudian contoh ufi tersebut dipres dingin menggunakan hydraulic press dengan tchanan tervaria-i : 10, 20 dan $30 \mathrm{Kg} / \mathrm{Cm}^{2}$, waktu pengepresan selama 15 detik. $1 . \mathrm{em}$. digunahin atd.-

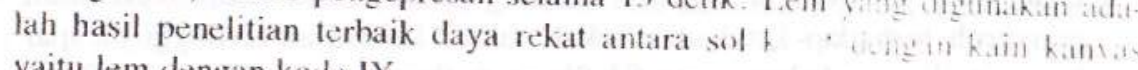
yaitu lem dengan kode IX.

Kemudian contoh uji tersebut disimpan dalam ruing homlisi soma minggu, setelah I minggu contoh uji dipotong-potong dengan lchar matsing masing : $6 \mathrm{~mm}$. Panjang : $100 \mathrm{~mm}$, (lebar $30 \mathrm{~mm}$ dipotong menjadi 5 con toh uji). Cara rersebut dimaksudkan untuk mempormudih perlakitan das berdasarkan cara uji ASTM D 1876.

Pemotongan dilakukan setelah satu minggu supaya keting shinggat tidath mempengaruhi kerekatan.

kondisi. Selanjutnya kompon tersebut dibuat slab untuk pemhuatan contoh uji.

- Sebelum dibuat slah dilakukan uji curing time untuk memectathui wethtu kemasakan karel yang optimum.

- Pencetakan dilakukan dengen hydraulic press dengan tekanan $150 \mathrm{Kg}$ $\mathrm{Cm}^{2}$, suhu $150^{\circ} \mathrm{C}$, wahtu sesuat dengan waktu optimum whimisasi padat ketebalan $3 \mathrm{~mm}$.

Prosedur pengujian :

Pengujian dilakukan terhadap kekerasan dan ketahanan rehat lema antara sol sepatu dengan kain kanvas sehatgai atasan sepatu.

1. Kekerasan

Pengujian dilakukan dengan menggunakan "Shore A Durometer", tohal

Pengujian ketahanan rekat :

Pengujian dilakukan dengan menggunakan alat uji tegangan putus dengan behan maksimal 0 - $10 \mathrm{Kg}$ paskal.

Cara uji : Pasang cuplikan pada penjepit yang ada pada alat. Lapisan yang satu tetap sedangkan lapisan yang lain ditarik kehawah, jalankan alat penarik dengan kecepatan : $250 \mathrm{~mm} / \mathrm{menit}$ sampai lapisan terbuka seluruhnya.

$$
\text { Perhitungan : } \frac{F}{1}=\mathrm{N} / 6 \mathrm{~mm}
$$

Vol. XII No. 22 Th. 1996/1997 
Keterangan : $\mathrm{F}=$ behan

I = lebar cuplikan

$\mathrm{N}=$ satuan newton

$6 \mathrm{~mm}=$ lebar contoh $u j i$

\section{HASIL PENELITIAN DAN PEMBAHASAN}

\section{Hasil Penelitian}

Hasil penelitian merupakan hasil perhitungan statistik dari hasil uji fisika pengaruh kekerasan kompon sol karet sepatu kanvas dengan daya rekat lem. Data hasil uji kekerasan dan ketahanan rekat dengan variasi kekerasan sol karet dan tekanan pres dapat dilihat pada lampiran (tahel : 2, 3 dan 4)

\section{Pembahasan}

\section{Kekerasan}

Hasil uji kekerasan menunjukkan bahwa semakin banyak hahan pengisi Ca $\mathrm{CO}_{3}$ yang ditambahkan, kompon karet yang dihasilkan bertambah keras.

2. Ketahanan rekat

Dari hasil perhitungan statistik menunjukkan hahw'a faktor kekerasan berpengaruh terhadap ketahanan rekat, faktor kekerasan tertinggi dicapai oleh kompon dengan kekerasan : 53 Shore A (kompon B) dengan nilai rata-rata $=21,2259 \mathrm{~N} / 6 \mathrm{~mm}$, sedangkan faktor tekanan dan interaksinya tidak herbeda nyata. Bila dibandingkan SNI 12-0171-1987, pada tekanan $20 \mathrm{Kg}$ ' $\mathrm{Cm}^{2}$, semua hasil uji ketahanan rekat memenuhi persyaratan.

3. Perlakuan

Faktor lain yang bisa mempengaruhi ketahanan rekat adalah waktu peng asaran, kebersihan permukaan yang akan dilem, cara pengulasan (tebal tipis nya $\mathrm{em}$, perlakuan awal (treatment) ataupun dengan cara pengaktifan kembali. Cara pengaktifan kembali adalah setelah permukaan dilem, disimpan dulu selama 24 jam, kemudian dipanaskan dengan suhu $70-80^{\circ} \mathrm{C}$ selama 10-15 menit kemudian direkatkan dan dipres, akan tetapi dengan cara pengaktifan kembali ini tidak dilakukan dengan pertimhangan sol karet yang sudah masak kalau diaktifkan dengan panas sama dengan diaging sehingga bisa menurunkan sifat fisis karet. Pengaktifan kembali lehih cocok untuk sol atau fexing yang belum masak.

\section{KESIMPULAN}

1. Ketahanan rekat yang tertinggi dicapai pada kompon sol karet dengan kekerasan 53 Shore A (kompon B) dengan nilai rata-rata ketahanan rekat 21,2259 Newton/ $6 \mathrm{~mm}$.

2. Bila dibandingkan SNI 12-0171-1987, ketahanan rekat tersebut memenuhi persyaratan sepatu kanvas dengan sol karet untuk olah raga.

\section{DAFTAR PUSTAKA}

1. ASTM standard: Annual book of ASTM standard part 22, wood adhesive (1981)

2. Departemen Perindustrian : SNI 12-0171-1987 sepatu kanvas dengan sol karet untuk olah raga.

3. Harry S Kartz: John V Mileweski Hand book of tiller and reinforcement.

4. J Shield, B.Sc. : Adhesive hand book Sira Institute limited, Second edition (1976)

5. Siti Rochani, Ir, dkk : Penelitian sifat fisis dan che lem dari bahan dasar paistik Yogyakarta (1984)

6. Small Business Publication : "Rubber Technology and Manufacture" Roop Nagar Delhi.

7. Soepranoto, Drs, dkk : Laporan Penelitian pembuatan kompon karet untuk sol dan foxing sepatu kanvas, Yogyakarta (1988). 
Lampiran

Tabel 2 : Analisa sidik ragam (ANOVA) Pengaruh kekerasan kompon karet dengan ketahanan rekat.

\begin{tabular}{l|r|r|r|r|r|r|}
\hline \multirow{2}{*}{ Sumber } & dk & \multicolumn{1}{|c|}{ JK } & Rjk & F hitung & \multicolumn{2}{|c|}{ F rabel } \\
\cline { 5 - 7 } & & & $5 \%$ & $1 \%$ \\
\hline - Ulangan & 2 & 20,7624 & 10,3812 & & & \\
- Perlakuan & 17 & 613,8417 & - & & & \\
- Kekerasan & 5 & 403,6541 & 80,7308 & $8,8165^{*}$ & 2,490 & 3,605 \\
- Tekanan & 2 & 10,7030 & 5,3515 & 0,5844 & 3,275 & 5,285 \\
- Kekerasan & & & & & & \\
X tekanan & 10 & 199,4846 & 19,9484 & 2,1785 & 2,225 & 3,080 \\
- Kekeliru & 34 & 311,3279 & 9,1567 & & & \\
\hline - Jumlah & 53 & 945,9320 & & & & \\
\hline
\end{tabular}

* ada beda nyata

Terlihat bahwa $\mathrm{F}$ hitung untuk kekerasan lebih besar $\mathrm{F}$ tahel $5 \%$ maupun $1 \%$, sehingga dapat ditentukan kekerasan yang menunjukkan daya rekat paling tinggi. Dengan perhitungan Lsd $5 \%=2,8955$, diperoleh kompon karet yang memberikan ketahanan rekat lem tertinggi dicapai oleh kompon karet dengan kekerasan 53 Shore A.

Tabel 3.

Hasil uji kekerasan kompon dengan variasi bahan pengisi $\mathrm{Ca}_{3} \mathrm{CO}_{3}$ (Shore A).

\begin{tabular}{c|c|c|c|c|c|}
\hline \multirow{2}{*}{ Kompon } & \multirow{2}{*}{$\begin{array}{c}\text { Ca Co3 } \\
\text { (bagian) }\end{array}$} & \multicolumn{3}{|c|}{ ulangan } & \multirow{2}{*}{ Rata-rata } \\
\cline { 3 - 6 } & 65 & 52 & 52 & 52 & 52 \\
\hline A & 65 & 53 & 53 & 53 & 53 \\
B & 70 & 54 & 54 & 54 & 54 \\
C & 75 & 55 & 55 & 55 & 55 \\
D & 80 & 55 & 56 \\
E & 85 & 56 & 56 & 56 & 57 \\
F & 90 & 57 & 57 & 57 & 57 \\
\hline
\end{tabular}

Tabel 4 :

Hasil uji ketahanan rekat antara sol karet dan kain kanvas dengan variasi kekerasan dan tekanan $(\mathrm{N} / 6 \mathrm{~mm})$

libel 4: 1lasil uji kerahanan rekat antara sol karet dan kain kanvas dengan variasi kekcrasan dan tekanan $(\mathrm{N} / 6 \mathrm{~mm})$

\begin{tabular}{|c|c|c|c|c|c|c|}
\hline \multirow{2}{*}{$\begin{array}{l}\text { Kom } \\
\text { pon }\end{array}$} & \multirow{2}{*}{\begin{tabular}{|l|} 
Kekerasan \\
(Shore A)
\end{tabular}} & \multirow{2}{*}{$\begin{array}{l}\text { Tekanan } \\
(\mathrm{Kg} / \mathrm{Cm})\end{array}$} & \multicolumn{3}{|c|}{ Ulangan } & \multirow{2}{*}{ Rata-rata } \\
\hline & & & 1 & 2 & 3 & \\
\hline \multirow{4}{*}{$A$} & \multirow{4}{*}{52} & 10 & 11,9641 & 15,0041 & 10,7873 & 12,5851 \\
\hline & & 20 & 17.8481 & 9,0221 & 13,2389 & 13,3806 \\
\hline & & 30 & 12,6024 & 13,7293 & 15,7887 & 14,0401 \\
\hline & & X & 14,1382 & 12,5851 & 13,2716 & 13,3352 \\
\hline \multirow{4}{*}{$B$} & \multirow{4}{*}{53} & 10 & 16,6713 & 25,3011 & 28,7334 & 23,5686 \\
\hline & & 20 & 22.9475 & 25.497 .3 & 23,0456 & 23,8301 \\
\hline & & 30 & 14,0235 & 21,0842 & 13,7293 & 16,2790 \\
\hline & & $\overline{\mathrm{X}}$ & 17.8807 & $23.960 \mathrm{~s}$ & $21 \ldots$ & 21,2259 \\
\hline \multirow{4}{*}{ C } & \multirow{4}{*}{54} & 10 & 13,1409 & 14,5138 & 15,1022 & 14.2523 \\
\hline & & 20 & 15,1022 & 14,1215 & 17,7497 & 15,6578 \\
\hline & & 30 & 19,0249 & 14,2196 & 17,7378 & 16,9941 \\
\hline & & $\bar{X}$ & 15,7560 & 14.2849 & 16,8632 & 15,6347 \\
\hline \multirow{4}{*}{ D } & \multirow{4}{*}{5.5} & 10 & 14,7099 & 17,0635 & 14,5138 & 15,4090 \\
\hline & & 20 & 15,1022 & 14,7099 & 13,7293 & 14,5138 \\
\hline & & 30 & 17,6519 & 25,8895 & 15,1022 & 19,5478 \\
\hline & & $\bar{X}$ & 15,8213 & 19,2209 & 14,4484 & 16,4902 \\
\hline \multirow{4}{*}{$E$} & \multirow{4}{*}{56} & 10 & 9,8066 & $10,983.5$ & 13,5332 & 15,4090 \\
\hline & & 20 & 18,0442 & 16,6713 & 12,7486 & 15,8213 \\
\hline & & 30 & 11,2776 & 10,5911 & 11,7679 & 11,2122 \\
\hline & & $\bar{X}$ & 13,0428 & 12,7486 & 12,6832 & 12,7248 \\
\hline \multirow{4}{*}{$\mathrm{F}$} & \multirow{4}{*}{57} & 10 & 13,9254 & 18,0442 & 13,9254 & 15,0745 \\
\hline & & 20 & 11,7679 & 16,4752 & 19,0249 & 15,7526 \\
\hline & & 30 & 17.8481 & 17,6519 & 13,7293 & 16,4097 \\
\hline & & $\overrightarrow{\mathrm{X}}$ & 14,5138 & 17.3904 & 15,5598 & 15,7458 \\
\hline
\end{tabular}

Vol. XII No. 22 Th. 1996/1997 